\title{
An introduction to Stephen C. Pepper's philosophical system via World Hypotheses: A Study in Evidence
}

\author{
FRANKLIN M. BERRY \\ California State University, Fresno, California
}

\begin{abstract}
Attention was called to the pregnant philosophical contribution of Stephen C. Pepper and to contemporary applications of his thought within various fields, especially psychology. Special attention was also called to the fact that general experimental psychologists as a group do not appear to be familiar with Pepper's World Hypotheses text. This writing was designed to serve as an introduction to this work and thereby to Pepper's philosophical system; this effort was directed expressly at members of The Psychonomic Society, most of whom are experimental psychologists.
\end{abstract}

A number of contemporary scholars have attempted to gain a better understanding of certain salient issues within their respective disciplines by relying upon ideas first expressed by Stephen C. Pepper (1891-1972) in his World Hypotheses: A Study in Evidence (Pepper, 1942). As a concrete example of this fact, one can turn to a recent special issue of the Journal of Mind and Behavior entitled "The Pepper Papers" (see Effron, 1982). In this single issue, Pepper's ideas were applied to music, to literature, to metaphilosophy, to aesthetics, and to historical psychology.

A number of contemporary psychologists have likewise applied Pepper's ideas, as captured in his World Hypotheses text, to their respective specialties (e.g., Berry 1983). In particular, the contribution of developmentalexperimental psychologists must be recognized. It was this group of psychologists who first rediscovered Pepper's classical work and introduced it to psychology via their efforts to clarify their metatheoretical analyses of mechanistic versus organismic research strategies within developmental psychology (Overton \& Reese, 1973; Reese \& Overton, 1970). The important contribution of a group of clinical psychologists who likewise "rediscovered" Pepper's World Hypotheses, apparently independently of the developmentalists, must also be recognized. It was this group of psychologists who created and validated a Pepper-inspired test, the World Hypotheses Scale, and successfully applied it to an investigation of group psychotherapy (Bethel, 1975; Fontana, Dowds, \& Bethel, 1976; Harris, Fontana, \& Dowds, 1977). ${ }^{1}$

Many other psychologists have also relied on Pepper's World Hypotheses text as a source of important ideas for their respective specialties. Sarbin's (1977) call for a

Some of the content expressed here was presented in an earlier paper (see Berry, 1982) sponsored by the Division of Philosophical and Theoretical Psychology. The author's mailing address is: Arizona School of Psychology, Metropolitan University of the Southwest, 15421 North 1st Avenue, Phoenix, AZ 85023. "new psychology" modeled on the dramatic act (or the contextualistic world hypothesis) was heavily dependent on Pepper's text; the same can be said for Sarbin and Coe's (Coe, 1978; Sarbin \& Coe, 1979) analysis of the philosophical foundations of the field of psychopathology and the phenomenon of hypnosis. Indeed, in recent years one can find citations of Pepper's World Hypotheses text within the domains of industrial/organizational psychology (Payne, 1976), psychoanalysis (McGuire, 1979), Christian psychology (Larzelere, 1980), general psychology (Tyler, 1981), and behavioral medicine (Schwartz, 1982). But what about the field of general experimental psychology? Where are the citations to Pepper's text by experimental psychologists who work in specialties other than developmental psychology?

Despite the apparently widespread appreciation of the importance of Pepper's ideas for psychology, a search of the Social Science Citation Index for the years 1977-1982 suggests that World Hypotheses has largely escaped the notice of psychologists working in the domain of general experimental psychology. The present effort was designed to serve as a "corrective" to this state of affairs. By calling attention to Pepper's ideas in this journal, it seemed reasonable to expect that a number of general experimental psychologists would begin to explore Pepper's ideas and to apply them to their respective research specialties. To this end, the plan of this presentation was to provide a conceptual overview of the richness of ideas contained in Pepper's World Hypotheses text. The sheer length of Pepper's book and the limitations of space herein have both served to make this a somewhat superficial introduction to some profound ideas.

\section{PEPPER'S WORLD HYPOTHESES: A STUDY IN EVIDENCE}

This major philosophical work was first published in 1942 , and it is still in print. It is interesting to note that 
a descriptive phrase printed on the jacket of this book probably worked to ensure that most American experimental psychologists of that era (circa 1940) would never open the book: "Prolegomena to systematic philosophy and a complete survey of metaphysics." Today, however, as previously described, many psychologists have read and studied this text. For the purpose of describing it succinctly, World Hypotheses can be conceived of as consisting of three interrelated contributions: (1) a theory of knowledge based on the progressive refinement of doubtful commonsense knowledge; (2) "root metaphor theory," that is, a theory of the origin of world hypotheses in commonsense metaphor; and (3) an analytical examination of the six world hypotheses that have served as the respective fundamental assumptions for competing schools of philosophy throughout recorded history. Let us briefly examine each of these contributions.

\section{The Theory of Knowledge}

Pepper's theory of knowledge is one of cognitive refinement. The basic idea is that commonsense fact contains some core of truth, but is also to be doubted; by progressive rational criticism of commonsense knowledge, it is possible to move to "rough" knowledge and ultimately to highly criticized or refined knowledge. Pepper postulated two parallel mechanisms for moving from doubtful to certain knowledge: (1) "multiplicative corroboration"-corroboration based on interobserver agreement ("corroboration of man with man"); and (2) "structural corroboration"-corroboration based on converging factual agreement ("corroboration of fact with fact"). Pepper also offered an analysis of the differential roles played by multiplicative versus structural corroboration in science, logic, mathematics, and philosophy (see Pepper, 1942, chap. 1-3, especially chap.3).

\section{Root Metaphor Theory}

Pepper's root metaphor theory is concerned with the origin of hypotheses, especially world hypotheses, which are hypotheses of unlimited scope. The following quote illustrates the nature of root metaphor theory and its relationship to world hypotheses:

A man desiring to understand the world looks about for a clue to its comprehension. He pitches upon some area of commonsense fact and tries to understand other areas in terms of this one. This original area becomes his basic analogy or root metaphor. He describes as best he can the characteristics of this area, or, if you will, discriminates its structure. A list of its structural characteristics becomes his basic concepts of explanation and description. We call them a set of categories. In terms of these categories he proceeds to study all other areas of fact whether uncriticized or previously criticized. He undertakes to interpret all facts in terms of these categories. As a result of the impact of these other facts upon his categories, he may qualify or readjust the categories, so that a set of categories commonly changes and develops. Since the basic analogy or root metaphor normally (and probably at least in part necessarily) arises out of common sense, a great deal of development and refinement of a set of categories is required if they are to prove adequate for a hypothesis of unlimited scope. Some root metaphors prove more fertile than others, have greater powers of expansion and of adjustment. These survive in comparison with the others and generate the relatively adequate world theories. (pp. 91-92)

This passage illustrates the fundamental importance of common sense in human cognition and, by implication, the interrelationship between cognitive refinement (multiplicative vs. structural corroboration), metaphor making, hypothesis generation, and hypothesis articulation. This statement also seems to be a clear articulation of a kind of theory-laden constructivism, one in which preexisting cognitive categories guide the perceiver/ observer in his or her observations of the world and one in which the "observations" in turn guide the cognitive refinement of these same categories within the perceiver/thinker. This reciprocal process has apparently been "acted out" by great thinkers throughout history and, according to Pepper, has been responsible for all of the great philosophical systems-each of which arose from a commonsense metaphor that was refined into a world hypothesis (see Pepper, 1942, chap. 4 and 5). Let us now turn to a brief consideration of Pepper's views of world hypotheses.

\section{The World Hypotheses Identified by Pepper}

The six hypotheses that Pepper identified as world hypotheses (or world theories) are: animism, mysticism, formism, mechanism, organicism, and contextualism. Because Pepper's analysis has shown that the first two hypotheses are inadequate, they will be ignored here. The remaining four hypotheses have served to undergird different philosophies throughtout recorded history; it is worth emphasizing again that each hypothesis owes its origin to the root metaphor method, which begins in commonsense experience.

\begin{abstract}
The suggestion is that world hypotheses get started like any man's everyday hypothesis framed to solve a puzzling practical problem. The man looks back over his past experience for some analogous situation which might be applicable to his present problem. Similarly, a philosopher, puzzled about the nature of the universe, looks about for some pregnant experience that appears to be a good sample of the nature of things. This is his root metaphor. He analyzes his sample, selects its structural elements, and generalizes them as guiding concepts for a world hypothesis of unlimited scope. This set of concepts becomes the set of categories of his world hypothesis. (Pepper, 1982, p. 199)
\end{abstract}

Pepper's four relatively adequate world hypotheses, as well as the root metaphor for each, are as follows:

(1) The formistic hypothesis (formism). The commonsense perception of similarity between two things is the root metaphor for this hypothesis. A round orange and a round ball, according to this hypothesis, are similar in the sense that they both share the specific character of "roundness" (they share the same "form," and this form constitutes a class or category in which many particulars may "participate"). Two or more particulars are "related" via the formistic hypothesis if they both participate in a common character or are members of 
the same type, class, or ideal form. Formistic philosophical systems (e.g., Plato and Aristotle) assume that the phenomena of the world can be understood by assigning them to specific classes or types.

(2) The mechanistic hypothesis (mechanism). The everyday perception of the operation of machines serves as the root metaphor for this hypothesis. The operation of a lever and fulcrum is an example of a commonsense perception that can serve as the root metaphor for mechanism; the "machine" is divisible into parts that interact with one another in a cause-and-effect mode (e.g., "force" is applied to the lever to raise some object). Mechanistic philosophical systems (e.g., Laplace and Locke) assume that the phenomena of the world can be understood by analyzing them into their "working parts," each with a specific location, and by specifying how each part is acted on by other parts, all within a specifiable antecedent-consequent time sequence.

(3) The contextualistic hypothesis (contextualism). The historic event, as it is experienced intuitively, as it is happening, in a specific setting involving specific action and specific actors/agents, is the root metaphor for the contextualistic hypothesis. According to Pepper (1942, p. 232), "The real historical event, the event in its actuality, is when it is going on now, the dynamic dramatic active event. We may call it an 'act,' ... it is an act in and within its setting, an act in its context." Moreover, such "acts or events are all intrinsically complex, composed of interconnected activities with continuously changing patterns. They are like incidents in the plot of a novel or drama. The are literally incidents of life" (p. 233). Contextualistic philosophical systems (e.g., James's pragmatism) assume that the phenomena of the world can be understood by recognizing that all events are unique and must, therefore, be related to the specific context in which they occur, which are themselves constantly changing (like the intuitive experience of the stream-oflife incidents on which this hypothesis is modeled).

(4) The organismic hypothesis (organicism). The everyday perception of dynamic organisms living out their lives is the source of the root metaphor for this hypothesis. For example, the commonsense perception of the transformation of a seed into a tree is one example of an everyday perception that can serve as the origin of the organic metaphor. The specific root metaphor for organicism is the complex, integrated organic process that is presumed to underlie the development of a phenomenon, which begins in one form, then undergoes change toward some end, and finally culminates in another form that must have been implicit in the earlier form(s). Organismic philosophical systems (e.g., Hegel's dialectics) assume that the phenomena of the world exist as parts of some larger unfolding whole that is in the process of developing toward some final end state that is an integrated whole.

\section{CONCLUSION}

In closing, I would like to emphasize again that the present cursory examination of Pepper's World Hypoth- eses text was designed to draw the attention of general experimental psychologists to this work. For those readers who do intend to pursue a study of Pepper's contribution, Kaye's (1977, pp. 347-355) summary of Pepper's philosophical system may prove to be a useful preview to such study.

\section{REFERENCES}

Berry, F. M. (1983, August). Philosophical world views: Some implications for clinical and experimental psychology. Paper presented at the meeting of the American Psychological Association, Anaheim, CA.

Bethel, M. H. (1975). The World Hypotheses Scale: A study of world organizing systems. Unpublished doctoral dissertation, Clark University, Worcester, MA.

CoE, W. C. (1978). The credibility of posthypnotic amnesia: A contextualists' [sic] view. International Journal of Clinical and Experimental Hypnosis, 26, 218-245.

Efron, A. (Ed.) (1982). The Pepper papers, a symposium on the metaphilosophy of Stephen C. Pepper: Root metaphor theory [Special issue]. Journal of Mind and Behavior, 3(3 \& 4).

Fontana, A. F., Dowds, B. N., \& Bethel, M. H. (1976). A.A. and group therapy for alcoholics: An application of the World Hypotheses Scale. Journal of Studies on Alcohol, 37, 675-682.

Harris, M., Fontana, A. F., \& Dowds, B. N. (1977). The World Hypotheses Scale: Rationale, reliability and validity. Journal of Personality Assessment, 41, 537-547.

KAYE, H. (1977). Early experience as the basis for unity and cooperation of "differences." In N. Datan \& H. W. Reese (Eds.), Life-span developmental psychology: Dialectical perspectives on experimental research (pp. 343-364). New York: Academic Press.

LARZELERE, R. E. (1980). The task ahead: Six levels of integration of Christianity and psychology. Journal of Psychology and Theology, 8, 3-11.

McGuire, M. T. (1979). Stephen Pepper, world hypotheses and the structure of metapsychology. International Review of PsychoAnalysis, 6, 217-230.

Overton, W. F., \& Reese, H. W. (1973). Models of development: Methodological implications. In J. R. Nesselroade \& H. W. Reese (Eds.), Life-span developmental psychology: Methodological issues (pp. 65-86). New York: Academic Press.

PAYNe, R. (1976). Truisms in organizational behaviour. Interpersonal Development, 6, 203-221.

PePper, S. C. (1942). World hypotheses: A study in evidence. Berkeley, CA: University of California Press.

PePPER, S. C. (1982). Metaphor in philosophy. Journal of Mind and Behavior, 3, 197-205.

Reese, H. W., \& Overton, W. F. (1970). Models of development and theories of development. In L. R. Goulet \& P. B. Baltes (Eds.), Life-span developmental psychology: Research and theory (pp. 115-145). New York: Academic Press.

Sarbin, T. R. (1977). Contextualism: The world view for modern psychology. In A. W. Landfield (Ed.), Nebraska Symposium on Motivation: Vol. 24. Personal construct psychology (pp. 1-41). Lincoln: University of Nebraska Press.

Sarbin, T. R., \& Coe, W. C. (1979). Hypnosis and psychopathology: Replacing old myths with fresh metaphors. Journal of Abnormal Psychology, 88, 506-526.

Schwartz, G. E. (1982). Testing the biosocial model: The ultimate challenge facing behavioral medicine? Journal of Consulting and Clinical Psychology, 50, 1040-1053.

TYLER, L. E. (1981). More stately mansions-psychology extends its boundaries. Annual Review of Psychology, 32, 1-20.

\section{NOTE}

1. It is helpful to note that Harris and Bethel are one in the same person (i.e., M. Harris = M. H. Bethel).

(Manuscript received for publication May 7, 1984.) 